\section{A) Check for updates}

Cite this: Dalton Trans., 2020, 49 14758

Received 17th August 2020 Accepted 1st October 2020 DOI: $10.1039 / \mathrm{d} 0 \mathrm{dt} 02890 \mathrm{~h}$ rsc.li/dalton

\title{
Frontiers in the solution-phase chemistry of homoatomic group 15 Zintl clusters
}

\begin{abstract}
Bono van IJzendoorn (ID) and Meera Mehta (D)*
Although discovered more than a century ago, the study of Zintl anions is experiencing a renaissance. Initial investigations on Zintl anions were focused on the structure, bonding, and physical properties of both the solid-state Zintl phases and solution-state solvated salts. Advances over the last few decades included their reactivity with transition metals where both exo-coordination and encapsulation have been observed, organic derivatization, their oligomerisation chemistry, and the preparation of heteroatomic systems. Reports on these developments have been previously discussed and reviewed. Herein, we present the most recent developments in the solution-state chemistry of homoatomic group 15 Zintl clusters and an outlook for the field. We believe frontiers in this area are best represented by recent additions to the library of homoatomic polybismuthide clusters, new synthetic routes for the preparation and functionlisation of homoatomic group 15 clusters, and small molecule activation using group 15 homoatomic Zintl clusters.
\end{abstract}

\section{Historical perspective}

The earliest report on the formation of a Zintl ion dates to 1891 from Joannis, when he noted a stark colour change from blue to green upon dissolving lead into a liquid ammonia solution of sodium. ${ }^{1}$ Kraus made a similar observation upon the addition of tin to an ammoniacal sodium solution, this time affording a deep-red colour. ${ }^{2}$ The presence of homoatomic polyanions of the general formula $\left[\mathrm{E}_{9}^{\mathrm{IV}}\right]^{4-}\left(\mathrm{E}^{\mathrm{IV}}=\mathrm{Sn}, \mathrm{Pb}\right)$ gives rise to these highly coloured solutions, though the extract composition of these anions was only determined much later by Eduard Zintl. The composition of Zintl's eponymous ions was determined primarily using potentiometic titration; from these studies $\left[\mathrm{Pb}_{9}\right]^{4-},\left[\mathrm{Sn}_{9}\right]^{4-},\left[\mathrm{Sb}_{7}\right]^{3-}$, and $\left[\mathrm{As}_{7}\right]^{3-}$ were identified. ${ }^{3-5}$ The following 60 years in the field were focused on improving the synthesis and isolation of these anions, as well as understanding subtle differences in their geometries and electronic structures. A landmark advancement in the synthesis and crystallization of these clusters was, upon the extraction of the salts in aprotic polar solvents, the use of polyethers as cation-sequestering agents, allowing for the structural characterization of many Zintl ions. It is generally understood that the temperature, solvent, and stoichiometry of the starting materials and cation-sequestering agents can have an enormous impact on the isolable Zintl ion.

Historically $\mathrm{P}_{4}$ activation by transition metals and maingroup systems provides a versatile route to phosphorus con-

Department of Chemistry, The University of Manchester, Oxford Road, Manchester, M13 9PL, UK. E-mail: meera.mehta@manchester.ac.uk taining products of varied nuclearity while by-passing the use of $\mathrm{PCl}_{3}$, a toxic feedstock. Consequently, this area has received significant attention and been previously reviewed in the literature. ${ }^{6-13}$ However, $\mathrm{P}_{4}$ as feedstock brings its own challenges, such as unpredictable reactivity and its pyrophoric nature. In principle, many of the transformations that have been explored with $\mathrm{P}_{4}$ can also be applied to the structurally related $\left[\mathrm{P}_{7}\right]^{3-} .{ }^{14}$ This trianion can be understood as three $\mathrm{P}^{-}$ ions inserted into adjacent $\mathrm{P}-\mathrm{P}$ bonds of $\mathrm{P}_{4}$. Additionally, of the group 15 clusters shown in Fig. $1,\left[\mathrm{P}_{7}\right]^{3-}$ has been the most extensively studied given its synthetic accessibility (readily prepared on a $30 \mathrm{~g}$ scale) and the presence of an NMR active handle $\left({ }^{31} \mathrm{P}, I=\frac{1}{2}, 100 \%\right.$ natural abundance).

Select examples of group 15 Zintl clusters are shown in Fig. 1 and have been previously discussed in the larger context of Zintl chemistry. ${ }^{15-21}$ Moreover, a review published in 2014

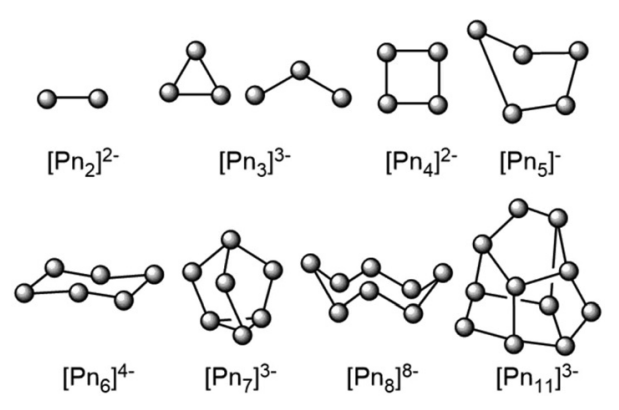

Fig. 1 Selected examples of known group 15 homoatomic cluster anions $(\mathrm{Pn}=\mathrm{P}, \mathrm{As}, \mathrm{Sb}, \mathrm{Bi})$. 
by the Goicoechea group focuses on the solution-phase chemistry of the heptapnitogen trianions, $\left[\mathrm{Pn}_{7}\right]^{3-} \cdot{ }^{14}$ In this work, we aim to discuss frontiers in the solution-phase chemistry of homoatomic group 15 Zintl clusters and provide an outlook for the field. The chemistry discussed in this article will be divided into four sections: (1) recent additions to the library of homoatomic group 15 Zintl clusters; (2) new synthetic strategies to homoatomic group 15 Zintl clusters; (3) subsequent small molecule activation; (4) outlook.

\section{Recent additions to the library of homoatomic group 15 Zintl clusters}

The $\left[\mathrm{Pn}_{7}\right]^{3-}$ trianion adopts a nortricyclane-like structure, in which three basal atoms are linked to an apical centre by three bridging atoms. Each of the bridging atoms behaves as a pseudo chalcogen atom, and consequently carries a formal charge of -1 . Homoatomic group 15 clusters are electron precise in their bonding, and can be explained by classical 2-centre, 2-electron bonding models. Clusters where the pnictogen is phosphorus, arsenic, and antimony have been previously accessed by solid phase alloys and solution phase methods, and their subsequent coordination chemistry, redox chemistry, Brønsted acid chemistry, functionalisation with group 14 and 15 substituents, and fragmentation and rearrangement has previously been discussed. ${ }^{14}$

Meanwhile, the heaviest naturally occurring group 15 element, bismuth, was found to prefer the formation of chain oligomers of the formula $\left[\mathrm{Bi}_{n}\right]^{n-}$ and squares of the formula $\left[\mathrm{Bi}_{4}\right]^{2-}$, both with some multiple bond character, ${ }^{22-27}$ as well as the singly bonded species $\left[\mathrm{Bi}_{4}\right]^{6-} \cdot{ }^{28}$ In 2015 , Sevov and coworkers were investigating mixed main-group/transition-metal clusters by exploring the coordination chemistry of $\mathrm{K}_{5} \mathrm{Bi}_{4}$ towards the chromium precursor $\left(\mathrm{C}_{6} \mathrm{H}_{6}\right) \mathrm{Cr}(\mathrm{CO})_{3}$ in the reduction-prone solvent pyridine. When they serendipitously discovered the reduction of the solvent to 4,4'-bipyridinium anion and formation of the heptabismuthide trianion $\left[\mathrm{Bi}_{7}\right]^{3-}$ (1). ${ }^{29}$ As with the other hepapnitogenide trianions, single crystal X-ray diffraction studies revealed a nortricyclane cage with four 3-connected (apical atom: Bi1; basal atoms: Bi5, Bi6, Bi7) and three 2-connected (linking atoms: Bi2, Bi3, Bi4) atoms as shown in Fig. 2. Three sets of distances can be defined with this shape: (A) apical-linking; (B) linking-basal;

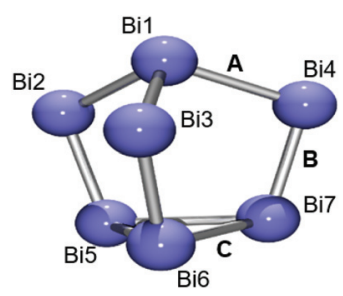

Fig. 2 Pov-Ray ball-and-stick image of 1. Countercations omitted for clarity. Blue: bismuth.
Table 1 Mean bond lengths for $A, B$, and $C$ of $\left[P n_{7}\right]^{3-}(P n=P, A s, S b, B i)$

\begin{tabular}{lllll}
\hline Mean bond length $(\AA)$ & {$\left[\mathrm{P}_{7}\right]^{3-}$} & {$\left[\mathrm{As}_{7}\right]^{3-}$} & {$\left[\mathrm{Sb}_{7}\right]^{3-}$} & {$\left[\mathrm{Bi}_{7}\right]^{3-}$} \\
\hline A & 2.204 & 2.432 & 2.78 & 2.93 \\
B & 2.150 & 2.399 & 2.70 & 2.90 \\
C & 2.255 & 2.498 & 2.86 & 3.07
\end{tabular}

(C) basal-basal. Mean bond lengths for A, B, and C are tabulated in Table 1 for $\left[\mathrm{Pn}_{7}\right]^{3-}$, where $\mathrm{Pn}=\mathrm{P}, \mathrm{As}, \mathrm{Sb}$, and $\mathrm{Bi}^{14,29}$ In good agreement with the other heptapnitogenide trianions, the bond distances of $\left[\mathrm{Bi}_{7}\right]^{3-}$ increase in the order $\mathrm{B}>\mathrm{A}>$ C. Furthermore, the ratio between $\mathrm{B}: \mathrm{A}: \mathrm{C}$ bond distances for all species are also consistent $(\mathrm{B}: \mathrm{A}: \mathrm{C}=1: 1.022: 1.065$ for $\mathrm{P}$; $1: 1.025: 1.069$ for As; $1: 1.015: 1.061$ for $\mathrm{Sb} ; 1: 1.011: 1.060$ for Bi). Eduard Zintl first proposed the existence of this compound over 80 years ago, ${ }^{4}$ but before this report it could not be found and was thought to be the missing member of this family. This seminal work represents a completion of the $\left[\mathrm{Pn}_{7}\right]^{3-}$ series.

It was also found that in the absence of the chromium reagent, the $\left[\mathrm{Bi}_{11}\right]^{3-}$ cluster was isolated instead, however the role of the organometallic additive in the selective crystallisation of $\left[\mathrm{Bi}_{7}\right]^{3-}$ vs. $\left[\mathrm{Bi}_{11}\right]^{3-}$ is not yet fully understood. ${ }^{29}$ The $\left[\mathrm{Bi}_{11}\right]^{3-}$ cluster was first reported a year earlier by the Dehnen group when $\left[\mathrm{GaBi}_{3}\right]^{2-}$ was solvated in pyridine. Upon recrystallisation, rather than the isolation of the mixed galliumbismuth dianionic cluster, $\left[\mathrm{Bi}_{11}\right]^{3-}$ and $\left[\mathrm{Bi}_{4}\right]^{2-}$ were found. ${ }^{30}$ Although the mechanism of this transformation is not understood, pyridine is again considered a non-innocent redoxactive solvent. In its reactivity with uranium, ${ }^{31}$ ruthenium, ${ }^{32}$ and cadmium ${ }^{33}$ the mixed group 13-group 15 tetrahedral Zintl precursors of the formula $\left[\mathrm{E}^{\mathrm{III}} \mathrm{Bi}_{3}\right]^{2-}\left(\mathrm{E}^{\mathrm{III}}=\mathrm{Ga}, \mathrm{Tl}\right)$ were found to couple bismuth centres together and yield larger metal coordinated polybismuthide clusters, while eliminating the group 13 element. In the case of ruthenium and cadmium, $\left[\mathrm{TlBi}_{3}\right]^{2-}$ was employed as the cluster precursor and the metal centres coordinated in an exo-fashion to the polybismuthide to afford $\left[\mathrm{Bi}_{9}\{\mathrm{Ru}(\mathrm{cod})\}_{2}\right]^{3-}(2)^{32}$ and $\left.\left[\left(\mathrm{Bi}_{7}\right) \mathrm{Cd}\left(\mathrm{Bi}_{7}\right)\right]^{4-}(3)\right)^{33}$ respectively. While, in the case of the actinide, $\left[\mathrm{GaBi}_{3}\right]^{2-}$ was employed as the cluster precursor and the uranium centre is encapsulated into a bismuth cluster with a nuclearity of 12 , [U@Bi $\left.{ }_{12}\right]^{3-}(4)$, shown in Fig. 3. ${ }^{31}$ Magnetic measurements of 4 revealed that the oxidation state of the uranium and change of the cluster are best described as $\left[\mathrm{U}^{4+} @ \mathrm{Bi}_{12}{ }^{7-}\right]^{3-}$, where the $\left[\mathrm{Bi}_{12}\right]^{7-}$ shell is a radical. This cage is a rare example of a main-group polyanion containing an odd number of electrons. Further supported by DFT investigations, it is thought that upon the inclusion of uranium the $\left[\mathrm{Bi}_{12}\right]^{6-}$ cage accepts an unpaired (f) electron from the actinide centre and is reduced.

In 2017, $\mathrm{Xu}$ and co-workers found that a solution of $\mathrm{KMnSb}$ and $\left(\mathrm{C}_{7} \mathrm{H}_{8}\right) \mathrm{Mo}$ in ethylenediamine afforded a mixture of anions, tetraanion $\left[\mathrm{Sb}_{4}\left\{\mathrm{Mo}(\mathrm{CO})_{3}\right\}_{2}\right]^{4-}(5)$ and dianion $\left[\mathrm{Sb}_{10}\right]^{2-}$ (6). ${ }^{34}$ X-ray diffraction studies of 5 revealed two $\left[\mathrm{Sb}_{2}\right]^{2-}$ units coordinating in an $\eta-2$ mode with each Mo metal centre, to give a $\left[\mathrm{MoSb}_{2} \mathrm{MoSb}_{2}\right]$ core. Interestingly, no significant inter- 


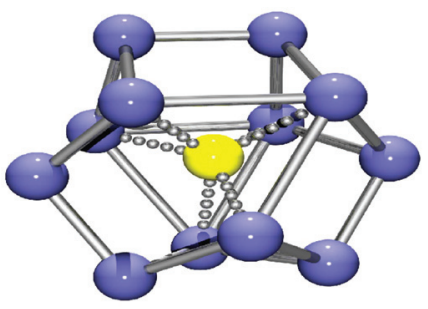

Fig. 3 Pov-Ray ball-and-stick image of 4 . Countercations omitted for clarity. Blue: bismuth; yellow: uranium.

action between the two $\left[\mathrm{Sb}_{2}\right]^{2-}$ units could be observed. It is noteworthy that $\mathbf{5}$ can be considered the kinetically stabilised $[\mathrm{Sb}=\mathrm{Sb}]^{2-}$ dianion, the lighter analogue of $[\mathrm{Bi}=\mathrm{Bi}]^{2-}$ which required the use of bulk counterions to be kinetically stable and isolated as the naked salt. ${ }^{24,25}$ Additionally, $\left[\mathrm{Sb}_{10}\right]^{2-}$ (6) can be thought of as two norbornadiene- $\mathrm{Sb}_{7}$ cages fused at four antimony atoms, in line with what would expect for its coordination chemistry. At the time of this report, both $\left[\mathrm{Sb}_{2}\right]^{2-}$ and 6 were missing members of the antimony polyanion family.

Finally, numerous new intermetallic clusters have been found where the metal centre does not occupy an endohedral site. First, Sun et al. reported on a reaction between $\mathrm{K}_{5} \mathrm{Sb}_{4}$ and $\left[\mathrm{Au}\left(\mathrm{PPh}_{3}\right) \mathrm{Ph}\right]$ in pyridine, which was found to yield the sandwich complex $\left[\mathrm{Sb}_{3} \mathrm{Au}_{3} \mathrm{Sb}_{3}\right]^{3-}$ (7). ${ }^{35}$ Later, they reported on the subsequently reactivity of this complex with $\mathrm{K}_{3} \mathrm{Sb}_{7}$ in ethylenediamine, which afforded $\left[\mathrm{Au}_{2} \mathrm{Sb}_{16}\right]^{4-}(8) .{ }^{36}$ Whereas reaction of $\mathrm{K}_{5} \mathrm{Sb}_{4}$ with $\mathrm{In}(\text { benzyl })_{3}$ gave a In/Sb Zintl cluster that can be

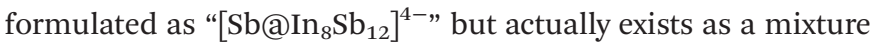
of $\left[\mathrm{Sb} @ \mathrm{In}_{8} \mathrm{Sb}_{12}\right]^{3-}(\mathbf{9})$ and $\left[\mathrm{Sb} @ \mathrm{In}_{8} \mathrm{Sb}_{12}\right]^{5-}(\mathbf{1 0}) .{ }^{37}$ Sun and coworkers were also able to prepare the isoelectronic bismuth clusters $\left[\mathrm{Bi} @ \mathrm{In}_{8} \mathrm{Bi}_{12}\right]^{3-}(\mathbf{1 1})$ and $\left[\mathrm{Bi} @ \mathrm{In}_{8} \mathrm{Bi}_{12}\right]^{5-}(\mathbf{1 2})$, albeit by a different synthetic route. ${ }^{38}$

Seminal work in the field was reported by Eichhorn and coworkers in 2003, with the preparation of an onion-skin cluster,

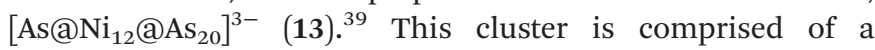
[As@ $\left.\mathrm{Ni}_{12}\right]^{3-}$ endohedral icosahedron encapsulated by an $\mathrm{As}_{20}$ dodecahedron. Recently, they reported on the related species $\left[\mathrm{Sb} @ \mathrm{Pd}_{12} @ \mathrm{Sb}_{20}\right]^{q-}(\mathbf{1 4 a}, \mathbf{b})$, where $q=3$ when $\mathrm{a}_{3} \mathrm{Sb}_{7}$ precursor is employed and $q=4$ when a $\mathrm{K}_{3} \mathrm{Sb}_{4}$ precursor is employed. ${ }^{40}$ Further solid-state and gas-phase investigations confirmed

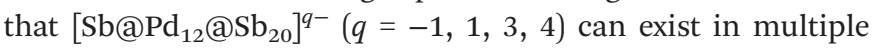
oxidation states. ${ }^{40,41}$

\section{New synthetic strategies to homoatomic group 15 Zintl clusters}

Zintl clusters are traditionally prepared by either low-temperature methods using liquid ammonia or high-temperature melts which have a reputation for requiring specialised equipment and vaporising the s-block metal in its preparation, requiring extreme care to avoid detonation. ${ }^{14}$ Given these limitations, alternative methods to prepare Zintl clusters are increasingly targeted.
Scheer has previously reviewed the area of $\mathrm{P}_{4}$ and $\mathrm{As}_{4}$ bond activation and coupling to yield polypnictogens of higher nuclearity at metal centres. ${ }^{8,9,13,42}$ The field of $\mathrm{P}_{4}$ activation has been reinvigorated by the use of singlet carbenes to affect $\mathrm{C}-\mathrm{P}$ bond formation. The final polyphosphide product $\left(\mathrm{P}_{n}\right.$; where $n=1,2,4,8,12$ ) formed is dependent on the electronic, relative s-donor/p-acceptor properties, and steric character of the carbene employed. ${ }^{8,11,12}$ Recently, Ghadwal et al. found that when a series C4/C5-ditopic anionic dicarbenes [Li (ADCAr)] were allowed to react with $\mathrm{P}_{4}$, 1,2,3-triphosphol-2-ide derivatives (Fig. 4; 15-18) were formed in high yield. ${ }^{43}$ Interestingly, $\mathrm{Li}_{3} \mathrm{P}_{7}$ is also formed in this transformation, shown in Fig. 4. It is believed that the cationic $\mathrm{P}^{3+}$ fragment is captured by the ADCs, while the $\mathrm{P}^{-}$nucleophile reacts with additional $\mathrm{P}_{4}$ to eventually form the $\left[\mathrm{P}_{7}\right]^{3-}$ polyphosphide. The $\mathrm{Li}_{3} \mathrm{P}_{7}$ salt could be subsequently isolated from the reaction mixture.

Whereas when Liddle et al. allowed a diuranium(v)-arenetetraanion complex (19) to react with $\mathrm{P}_{4}$, reductive cleavage was observed to yield a triuranium heptaphosphanotricyclane cluster (20). ${ }^{44}$ This cluster was reported as the first example of a molecular actinide $\left[\mathrm{P}_{7}\right]$ Zintl complex, with the magnetic moment of the crystalline material in solution being $4.67 \mu_{\mathrm{B}}$ at $298 \mathrm{~K}$, which is in good agreement with the powdered sample $\left(c f .4 .20 \mu_{\mathrm{B}}\right.$ at $\left.298 \mathrm{~K}\right)$. The X-ray crystal structure of 20 revealed formation of a $\left[\mathrm{P}_{7}\right]^{3-}$ core with $\eta^{2}$-coordination of all three uranium centres (shown in Fig. $5 ; 20$ ). Compound 20 was subsequently reacted with $\mathrm{Me}_{3} \mathrm{SiCl}, \mathrm{LiCl}, \mathrm{MeI}$, and PhI to afford $\left(\mathrm{SiMe}_{3}\right)_{3} \mathrm{P}_{7}, \mathrm{Li}_{3} \mathrm{P}_{7}, \mathrm{Me}_{3} \mathrm{P}_{7}$, and $\mathrm{Ph}_{3} \mathrm{P}_{7}$, respectively. The uranium containing by-product from these reactions was a uranium dimer with a bridged chloride (21), which could be convert back to the starting material using $\mathrm{KC}_{8}$. In the presence of excess $\mathrm{RX}\left(\mathrm{R}=\mathrm{Me}_{3} \mathrm{Si}, \mathrm{Li}, \mathrm{Me}, \mathrm{Ph} ; \mathrm{X}=\mathrm{Cl}, \mathrm{I}\right)$ and $\mathrm{P}_{4}$ it was found that the yield of the heptaphosphide derivative was quantitative in the first turnover and near $40 \%$ in the second turnover. Although only two turnovers could be tolerated in this reaction, it was demonstrated that 19 was a viable catalyst to convert $\mathrm{P}_{4}$ into $\left[\mathrm{P}_{7}\right]^{3-}$.

In 2016, when Schulz and co-workers allowed $\mathrm{Mg}(\mathrm{I})$ dimers, featuring $\beta$-diketiminate type ligands, to react with $\mathrm{Sb}_{2} \mathrm{R}_{4}(\mathrm{R}=$ $\mathrm{Me}, \mathrm{Et})$ a realgar-type $\left[\mathrm{Sb}_{8}\right]^{4-}$ polystibide core with four coordinated $\mathrm{Mg}$-substituents was obtained, as shown in Fig. 6 $\left[(\mathrm{LMg})_{4}\left(\mathrm{Sb}_{8}\right)\right] ;[22] .{ }^{45}$ Whereas, when gallanediyl LGa(I) $(\mathrm{L}=$

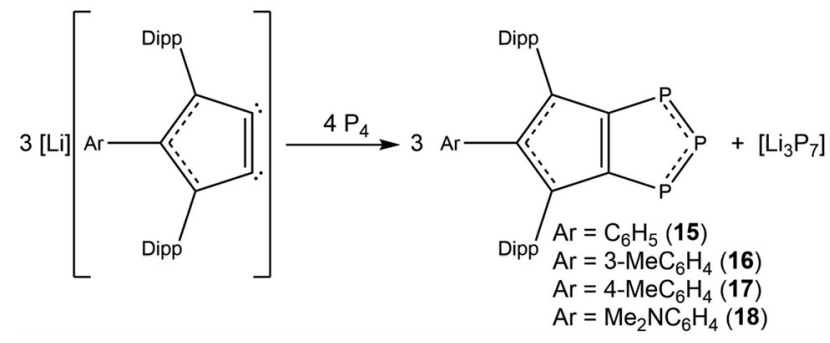

Fig. 4 Synthesis of 1,2,3-triphosphol-2-ide zwitterions and $\mathrm{Li}_{3} \mathrm{P}_{7}$ from fragmentation of $\mathrm{P}_{4}$ with [Li(ADCAr)]. 

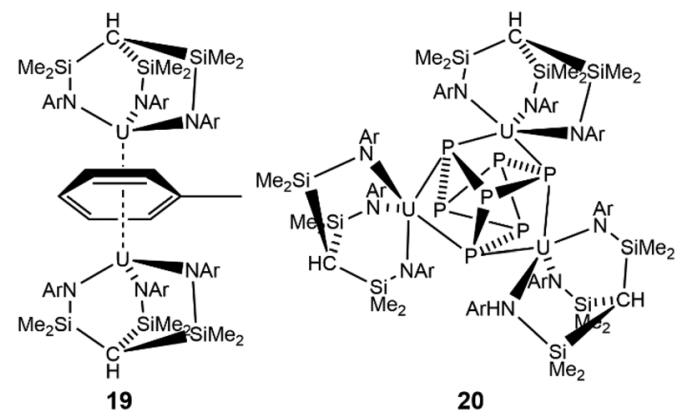
20
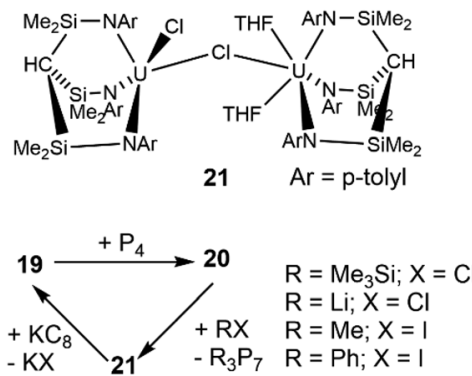

Fig. 5 Catalytic cycle for the catenation and functionalisation of $\mathrm{P}_{4}$ using RX.

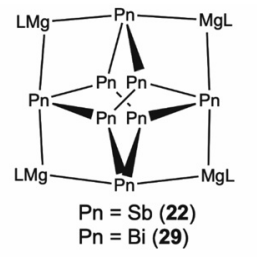

$$
\mathrm{L}(\mathrm{X}) \mathrm{Ga} \backslash_{\mathrm{Pn}^{\prime}}=\mathrm{Pn}_{\mathrm{Ga}(\mathrm{X}) \mathrm{L}}
$$$$
\mathrm{Pn}=\mathrm{Sb} ; \mathrm{X}=\mathrm{Cl} \text { (23a) }
$$

$\mathrm{Pn}=\mathrm{Sb} ; \mathrm{X}=\mathrm{NMeEt}(\mathbf{2 3 b})$

$\mathrm{Pn}=\mathrm{Sb} ; \mathrm{X}=\mathrm{NMe}_{2}(\mathbf{2 3 c})$

$\mathrm{Pn}=\mathrm{As} ; \mathrm{X}=\mathrm{Cl}(\mathbf{2 5 a})$

$\mathrm{Pn}=\mathrm{As} ; \mathrm{X}=\mathrm{NMe}_{2}(\mathbf{2 5 b}$

$\mathrm{Pn}=\mathrm{Bi} ; \mathrm{X}=\mathrm{Cl}(\mathbf{2 6 \mathrm { a } )}$

$\mathrm{Pn}=\mathrm{Bi} ; \mathrm{X}=\mathrm{NEt}_{2}$ (26b)
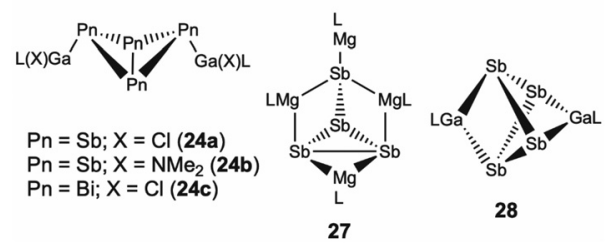

$\mathrm{Pn}=\mathrm{Sb} ; \mathrm{X}=\mathrm{NM}(24 b)$

$\mathrm{Pn}=\mathrm{Bi} ; \mathrm{X}=\mathrm{Cl}(24 \mathrm{c})$

Fig. 6 Recent examples of gallium and magnesium polypnictogen complexes.

$\beta$-diketiminate type ligands) were employed as the reductant with alkyl substituted antimony reagents no reaction was observed. However, moving to $\mathrm{SbX}_{3}$ (where $\mathrm{X}=\mathrm{Cl}$, NMeEt, $\mathrm{NMe}_{2}$ ) precursors resulted in reductive coupling for the antimony centres to give Ga-substituted distiene of the general formula $\left[(\mathrm{LGaX})_{2} \mathrm{Sb}_{2}\right](\mathbf{2 3 a}, \mathbf{b}, \mathbf{c})$ comprising of a $\mathrm{Sb}=\mathrm{Sb}$ double bond within the $\left[\mathrm{Sb}_{2}\right]^{2-}$ moiety. Upon heating these distiene were found to convert to $\left[(\mathrm{LGaX})_{2}\left(\mathrm{Sb}_{4}\right)\right.$; where $\mathrm{X}=\mathrm{Cl}$ (24a), $\mathrm{NMe}_{2}$ (24b)] complexes, presenting the $\left[\mathrm{Sb}_{4}\right]^{2-}$ dianion as the first $\mathrm{Sb}$ analogue of bicyclo[1.1.0]butane. ${ }^{46}$ Furthermore, it was found that reactions of gallanediyl $\mathrm{LGa}(\mathrm{I})$ with arsenic halides, arsenic nitrides, and bismuth nitrides was a general route to isolable metal functionalised dipnictene of the formula $[\mathrm{L}(\mathrm{x})$ $\mathrm{M}]_{2} \mathrm{Pn}_{2}\left[\mathrm{Pn}=\mathrm{As}\right.$ (25), Bi (26)]. ${ }^{47}$ Later in 2017, Schulz and coworkers also investigated both $\mathrm{Mg}(\mathrm{I})$ and $\mathrm{Ga}(\mathrm{I})$ reductants with
$\left[\mathrm{Cp}{ }^{*} \mathrm{Sb}\right]_{4}$, which formally contains a monovalent $\mathrm{Sb}$ atom. ${ }^{48} \mathrm{It}$ was found that in the case of the $\mathrm{Mg}(\mathrm{I})$ reductant, $\left[(\mathrm{LMg})_{4}\left(\mathrm{Sb}_{4}\right)\right]$ (27) was readily formed where the $\left[\mathrm{Sb}_{4}\right]^{2-}$ tetraanion coordinated three magnesium centres in a $\eta-2$ fashion and one magnesium terminal in a $\eta-1$ fashion, to give a $\mathrm{Mg}_{4} \mathrm{Sb}_{4}$ core. Meanwhile, the gallium reductant afforded a $\left[(\mathrm{LGa})_{2}\left(\mathrm{Sb}_{4}\right)\right]$ (28) complex, with both gallium centres coordinating in an $\eta$ 2 mode, and elimination $\mathrm{Cp}^{*}{ }_{2}$. Lastly, earlier this year, $\mathrm{LMg}(\mathrm{I})$ and $\mathrm{LGa}(\mathrm{I})$ reductants where reacted with bismuth precursors. ${ }^{49}$ Similar to the antimony chemistry, the Ga(I) reductant required the use of a bismuth halide to undergo reductive coupling and yield the $\left[\mathrm{Bi}_{4}\right]^{2-}$ core coordinated in a butterfly fashion, the $\mathrm{Bi}$ analogue of bicyclo[1.1.0]butane, $\left[(\mathrm{LGaCl})_{2}\left(\mathrm{Bi}_{4}\right)\right](\mathbf{2 4 c})$. While, the $\mathrm{Mg}(\mathrm{I})$ reagent reacted with $\mathrm{Bi}_{2} \mathrm{Ph}_{4}$ to afford a $\left[(\mathrm{LMg})_{4}\left(\mathrm{Bi}_{8}\right)\right]$ (29) complex, akin to 22 .

While, Roesky found direct access to molecular polystibide complexes from two reactive antimony sources. ${ }^{50}$ Previously, polystibide complexes had been reported from the reduction of organostilbine reagents and traditional coordination chemistry with Zintl clusters. ${ }^{51,52}$ At the time, elemental antimony had not been found to be viable reagent for the synthesis of metal-polypnictide complexes. To this end, Roesky et al. reacted samarocenes with $\mathrm{Sb}$ chunks and powder but observed no reaction. In an effort to move to more reactive elemental antimony, they explored antimony nanoparticles in this transformation. ${ }^{50}$ As a result of their drastically enlarged surface-tovolume ratio, metal nanoparticles are known to increase in reactivity with decreasing particle size. ${ }^{53}$ Upon the preparation of uniform spherical nanoparticles with an average diameter if $6.6 \pm 0.8 \mathrm{~nm}$, characterised by TEM studies, and subsequent reaction towards $\left[\mathrm{Cp}^{*}{ }_{2} \mathrm{Sm}\right]\left(\mathrm{Cp}^{*}=\right.$ pentamethylcyclopentadiene anion) the formation of the binuclear Sm complex 30 (Fig. 7), determined by single crystal X-ray crystallography, was observed. ${ }^{50}$ Prolonged heating and reaction times resulted in the formation of $\left[\left(\mathrm{Cp}^{*}{ }_{2} \mathrm{Sm}\right)_{4} \mathrm{Sb}_{8}\right](35)$ as the thermodynamically favoured product. In a similar fashion, when $\mathrm{Hg} / \mathrm{Sb}$ amalgam was allowed to react with $\left[\mathrm{Cp}^{*}{ }_{2} \mathrm{Sm}\right]$ the same thermodynamic
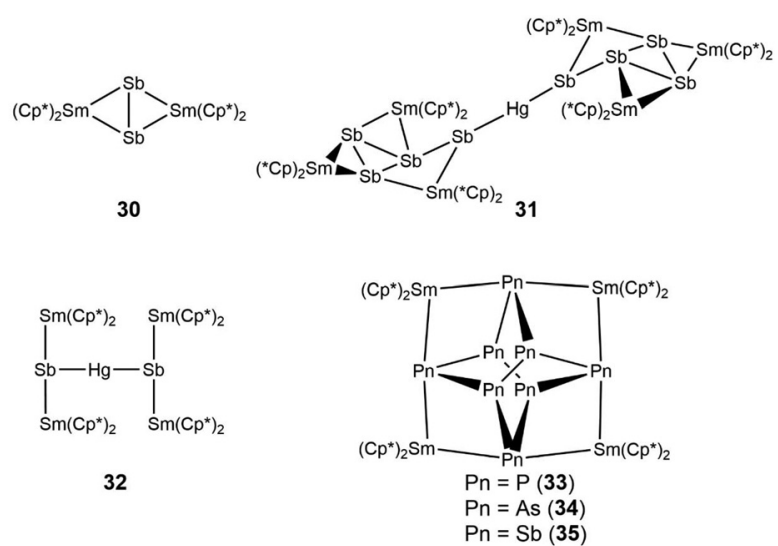

Fig. 7 Isolable intermediates from reaction of $\left[\mathrm{Cp}_{2}{ }_{2} \mathrm{Sm}\right]$ with activated elemental antimony (30-32); isolable samarium coordinated $\left[\mathrm{Pn}_{8}\right]^{4-}$ complexes, where $\mathrm{Pn}=\mathrm{P}, \mathrm{As}, \mathrm{Sb}$ (33-35). 
Sm coordinated $\left[\mathrm{Sb}_{8}\right]^{4-}$ could be obtained. However, now along with intermediate $\mathbf{3 0}$, the mercury containing intermediates 31 and 32 could also be observed. Later, Roesky reported arsenic nanoparticles, now with a diameter of $7.2 \pm 1.8 \mathrm{~nm}$, as a viable source to the related $\left[\left(\mathrm{Cp}_{2}{ }_{2} \mathrm{Sm}\right)_{4} \mathrm{As}_{8}\right]$ complex $34 .^{54} \mathrm{IR}$ spectra for $\left[\left(\mathrm{Cp}_{2}{ }_{2} \mathrm{Sm}\right)_{4} \mathrm{P}_{8}\right]^{55}$ (33; previously prepared using $\mathrm{P}_{4}$ as the polyphosphide source), $\left[\left(\mathrm{Cp}_{2}{ }_{2} \mathrm{Sm}\right)_{4} \mathrm{As}_{8}\right](34),{ }^{54}$ and $\left[\left(\mathrm{Cp}_{2}{ }_{2} \mathrm{Sm}\right)_{4} \mathrm{Sb}_{8}\right](35)^{49}$ are all in excellent agreement with one another. Furthermore, the samarium coordinated $\left[\left(\mathrm{Cp}^{*}{ }_{2} \mathrm{Sm}\right)_{4} \mathrm{Pn}_{8}\right](\mathrm{Pn}=\mathrm{P}(33)$, As $(34), \mathrm{Sb}(35))$ systems are structurally related to the magnesium coordinated $\left[(\mathrm{LMg})_{4} \mathrm{Pn}_{8}\right](\mathrm{Pn}$ $=\mathrm{Sb}(22), \mathrm{Bi}(29))^{50,54,55}$ systems mentioned earlier. ${ }^{45,49}$ While, reduction of $\left[\mathrm{Cp}{ }^{*} \mathrm{Fe}\left(\eta^{5}-\mathrm{As}_{5}\right)\right]$ with a samarocene derivative afforded $\left[\left(\mathrm{Cp}^{\mathrm{R}}{ }_{2} \mathrm{Sm}\right)_{2} \mathrm{As}_{7}\left(\mathrm{Cp}{ }^{*} \mathrm{Fe}\right)\right](36)$ which contains the $\left[\mathrm{As}_{7}\right]^{3-}$ cage. $^{56}$ These reports represent new synthetic strategies towards f-block polypnictides complexes by combining traditional organometallic chemistry and solid-state reagents. Recently, Chitnis and co-workers also reported on a similar $\left[\mathrm{Sb}_{8}\right]^{4-}$ core this time coordinating four $\mathrm{Sb}$ (III) ligands, attained by attempted deprotonation of $\mathrm{Sb}-\mathrm{H}$ bonds. ${ }^{57}$

Grützmacher and Gudat circumvented the use of solid-state methods in the heptaphosphide synthesis by reacting sodium and elemental phosphorus (red and white) in solution. ${ }^{58}$ It was found that a catalytic amount of naphthalene and a 1:1 solvent mixture of dimethoxyethane (DME):THF was necessary to selectively obtain $\mathrm{Na}_{3} \mathrm{P}_{7}$ in high yield. However, even after several days of heating under reduced pressure, $12 \mathrm{~mol} \% \mathrm{DME}$ was detected in the final product. Subsequent reaction of the DME coordinated $\mathrm{Na}_{3} \mathrm{P}_{7}$ with trimethylsilyl chloride allowed for clean isolation of the $\left(\mathrm{SiMe}_{3}\right)_{3} \mathrm{P}_{7}$ Zintl cluster.

Shatruk and co-workers were also able to obtain polyphosphides using a solution phase method. They employed the redox-inactive KOEt to activate red phosphorus in a mixture of THF and DME to afford combinations of $\left[\mathrm{P}_{5}\right]^{-},\left[\mathrm{P}_{16}\right]^{2-}$, and $\left[\mathrm{P}_{21}\right]^{3-}{ }^{59}$ It was found that the distribution of polyphosphides was highly solvent dependant, and could be expanded to affect the preparation of $\left[\mathrm{P}_{7}\right]^{3-}$ and $\left[\mathrm{P}_{11}\right]^{3-}$ polyphosphides. ${ }^{60}$ These reactions are thought to proceed via nucleophilic attack that initiates a cascade of disproportionation reactions and rearrangements. This work was expanded to implement a topdown approach for the activation of shelf-stable $\mathrm{P}(\mathrm{red}) \mathrm{using}$ organic solvents and convenient nucleophiles in a flow-reactor to attain soluble polyphosphides on continuous multi-gram scale. ${ }^{59}$ Mechanistically, this activation of $\mathrm{P}(\mathrm{red})$ with the KOEt alkoxide is drastically different from the reduction methods of elemental phosphorus that have been previously reported and the examples discussed earlier. $\mathrm{P}(\mathrm{OEt})_{3}$ is an observed byproduct from this nucleophilic attack, and could be extracted from the reaction mixture. The nucleophiles that activated $\mathrm{P}(\mathrm{red})$ were expanded to include other alkoxides (KOR; where $\mathrm{R}$ $=$ methyl, $n$-hexyl and $t$-butyl), thiolates (NaSR; where $\mathrm{R}=\mathrm{Me}$, Et, $n$-hex, i-Pr, $t$-Bu), and amides (KHMDS, LiHMDS, and LDA), with varying degrees of efficiency. ${ }^{59,60}$

Hänisch and Sundermeyer found that when methylcarbonate salts were allowed to react with $\mathrm{P}\left(\mathrm{SiMe}_{3}\right)_{3}$ the organic salts of $\mathrm{PCO}^{-}$could be attained. However, in a similar fashion when they reacted methylcarbonate salts with $\mathrm{Sb}$ $\left(\mathrm{SiMe}_{3}\right)_{3}$, rather than $\mathrm{SbCO}^{-}$salts, XRD analysis revealed the formation of $\left[\mathrm{P}(n \mathrm{Bu})_{3} \mathrm{Me}\right]_{3}^{+}\left[\mathrm{Sb}_{11}\right]^{3-} \cdot{ }^{61}$

These new wet synthetic strategies to polypnictogen clusters offer exciting new possibilities for academics without the equipment or technical know-how to prepare Zintl clusters using traditional methods. While significant advancements have been made with the polyphosphide systems, the heavier pncitogens are often isolated as an inorganometallic complex coordinating a Zintl core, rather than the naked polyanion. This functionalisation can be undesirable, hindering or contaminating the subsequent chemistry of these complexes. Thus, traditional synthetic routes to heavy group 15 Zintl clusters is still a robust and sought-after method for preparation.

\section{Subsequent small molecule activation}

While protonation and salt metathesis reactions, for example with alkyl halides, aryl halides, silyl chlorides, and germanium chlorides, to afford functionalised Zintl clusters have been extensively studied, ${ }^{14}$ examples of small molecule activation that go beyond surface functionalisation are limited.

In 2012, Goicoechea and co-workers explored the reactivity of $\left[\mathrm{HPn}_{7}\right]^{2-}(\mathrm{Pn}=\mathrm{P}, \mathrm{As})$ with carbodiimides and isocyanates. ${ }^{62-64}$ It was found that these substrates underwent hydrophosphination across the $\mathrm{C}=\mathrm{N}$ bond, as pictured in Fig. 8 (37a-40a; 37b-40b). Though the mechanism of this reactivity is not well known, deuterium labelling studies revealed that the hydrogen transferred from the pnictogen cage.

Later in 2013, Goicoechea also found that when $\left[\mathrm{Pn}_{7}\right]^{3-}(\mathrm{Pn}$ $=\mathrm{P}, \mathrm{As})$ clusters were allowed to react with alkynes a $\left[\mathrm{Pn}_{3}\right]^{-}$ fragment was transferred to afford 1,2,3-tripnictolides, an unusual class of cyclopentadienide analogue (shown in Fig. 9; 41a-47a; 41b-46b). ${ }^{65,66}$ The subsequent coordination chemistry of these phosphorus-containing analogues of cyclopentadienide was also undertaken by the Goicoechea group. In an effort to isolate the kinetic product, Korber later investigated $\mathrm{Cs}_{3} \mathrm{As}_{7}$ towards diphenylacetylene in liquid ammonia when the dianion (Z)-1,2-diphenylethenyl-heptaarsenide (Fig. 10; 48) was isolated. ${ }^{67}$ At this time, it was postulated that the hydrogen atom necessary to reduce the triple bond must be originating from the ammonia solvent, followed by $\mathrm{As}_{4}$ elimination. Although, the reaction mechanism for these transformations

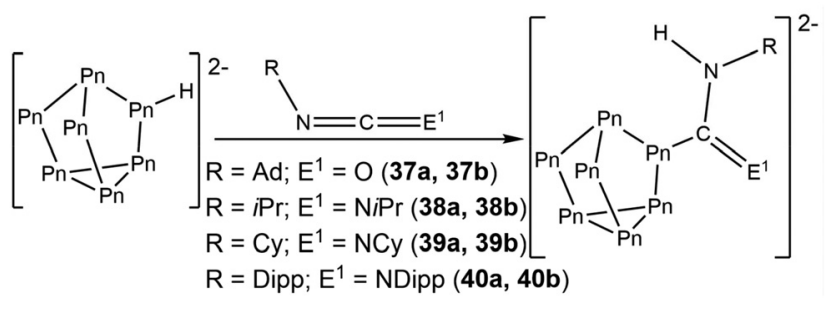

Fig. 8 Hydropnictination across $\mathrm{C}=\mathrm{N}$ bond of heteroallenes using $\left[\mathrm{HPn}_{7}\right]^{2-}(\mathrm{Pn}=\mathrm{P}\{37 \mathrm{a}-40 \mathrm{a}\}$, As $\{37 \mathrm{~b}-40 \mathrm{~b}\})$ clusters. 

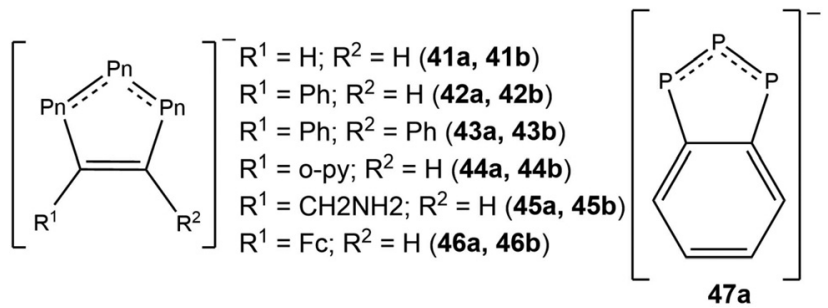

Fig. 9 1,2,3-Tripnictolide anions prepared from $\left[\mathrm{Pn}_{7}\right]^{3-}(\mathrm{Pn}=\mathrm{P}\{41 \mathrm{a}-$ $46 a\}$, As $\{41 a-46 b\})$ and alkynes.

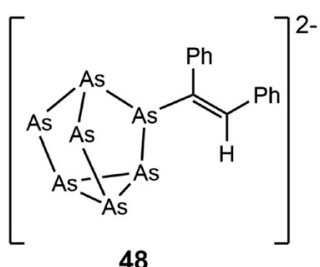

48

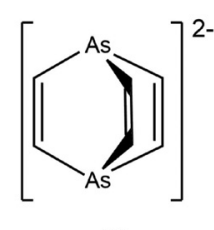

49
Fig. 10 Left: (Z)-1,2-Diphenylethenyl-heptaarsenide anion (48); right: diarsabarrelene (49).

are not well understood, it is believed to be reminiscent of azide 1,3-dipolar cycloaddition chemistry. ${ }^{68}$ Furthermore, it is known that $\left[\mathrm{Pn}_{7}\right]^{3-}$ and $\left[\mathrm{Pn}_{11}\right]^{3-}$ can transmute into one another, thus when $\mathrm{Rb}_{3} \mathrm{As}_{11}$ and $\mathrm{Cs}_{3} \mathrm{As}_{11}$ were investigated with acetylene in a similar fashion they were found to yield diarsabarrelene $\mathrm{As}_{2} \mathrm{C}_{6} \mathrm{H}_{6}$ (Fig. 9; 49). ${ }^{67}$

Finally, it was found that upon reaction with carbon monoxide, $\left[\mathrm{P}_{7}\right]^{3-}$ acts as a formal source of phosphide anions and afforded the phosphaethyanolate anion $[\mathrm{PCO}]^{-}$in $88 \%$ yield (if you consider $\mathrm{P}^{-}$as the limiting reagent; $\left[\mathrm{P}_{7}\right]^{3-}$ contains $3 \mathrm{P}^{-}$ units). ${ }^{69}$ This percent conversion appears to be low but is in line with the structural description of $\left[\mathrm{P}_{7}\right]^{3-}$ discussed above. This $[\mathrm{PCO}]^{-}$anion was first reported by Becker and later advanced by Grützmacher to be employed as a feasible feedstock. ${ }^{70-72}$ The subsequent chemistry of $[\mathrm{PCO}]^{-}$is now a separate field of study and has been reviewed by Grützmacher, Goicoechea, and Weber. ${ }^{73,74}$

\section{Outlook}

The study of Zintl clusters captures the imagination of academics for two primary reasons: (1) they can be considered molecular models for larger heterogenous structures; and (2) they can find potential applications as precursors to materials.

First, consider the relation between $\left[\mathrm{P}_{7}\right]^{3-},\left[\mathrm{P}_{11}\right]^{3-},\left[\mathrm{P}_{16}\right]^{2-}$, $\left[\mathrm{P}_{21}\right]^{3-}$, and red phosphorus. $\left[\mathrm{P}_{11}\right]^{3-}$ and $\left[\mathrm{P}_{16}\right]^{2-}$ represent larger more complex systems from coupling and fragmentation of $\left[\mathrm{P}_{7}\right]^{3-}$ clusters, and partially resemble red phosphorus, a difficult to study heterogenous material of a highly sustainable earth-abundant element. Functionalisation and subsequent reactivity studies with $\left[\mathrm{P}_{7}\right]^{3-}$ allows for solution state monitoring of chemistry that can later be exemplified with larger poly- phosphides and possibly even red phosphorus. Further, metal pnictogenides are finding increasing applications in electrochemical water-splitting cells and carbon dioxide reduction reaction, ${ }^{75-77}$ however an in situ study of these transformations remains a challenge. Preparing well defined reactive sites at these clusters followed by immobilisation could allow for a more systematic study of this work.

Next, in its reactivity with carbon monoxide $\left[\mathrm{P}_{7}\right]^{3-}$ has been observed to eliminate phosphide anions in a quantitative fashion. ${ }^{69}\left[\mathrm{Pn}_{7}\right]^{3-}$ acting as a controlled pnictogenide source offers opportunities for a solution-based bottom-up approach to make metal pnictogenides, both of transition metals and post-transition metals. Further, there have been strides made in the controlled oxidation and aggregation of group 14 Zintl clusters, namely $\left[\mathrm{Ge}_{9}\right]^{4-},\left[\mathrm{Ge}_{12}\right]^{7-}$, and $\left[\mathrm{Si}_{4}\right]^{4-}$, to access nanomaterials. ${ }^{78,79}$ By extending these methods to the group 15 systems, group 15 Zintl clusters have prospects as wetchemical precursors for pnitogen-containing nanomorphologies, with potential applications in electronics, in lithium-ion batteries, and as light emitting diodes. ${ }^{75}$ Along with developing better single-precursor methods to prepare known materials, recent advances in polybismuthide chemistry ${ }^{29,30}$ will pave the way to prepare new materials.

\section{Conflicts of interest}

There are no conflicts to declare.

\section{Acknowledgements}

We thank the EPSRC for funding a DTA studentship (B.V.I.).

\section{Notes and references}

1 A. C. R. Joannis, Hebd. Seances Acad. Sci., 1891, 113, 795798.

2 C. A. Kraus, J. Am. Chem. Soc., 1907, 29, 1557-1571.

3 E. Zintl and H. Kaiser, Z. Anorg. Allg. Chem., 1933, 211, 113-131.

4 E. Zintl and W. Dullenkopf, Z. Phys. Chem., Abt. B, 1932, 16, 183-194.

5 E. Zintl and A. Harder, Z. Phys. Chem., Abt. A, 1931, 154, 47-91.

6 B. M. Cossairt, N. A. Piro and C. C. Cummins, Chem. Rev., 2010, 110, 4164-4177.

7 M. Caporali, L. Gonsalvi, A. Rossin and M. Peruzzini, Chem. Rev., 2010, 110, 4178-4235.

8 M. Scheer, G. Balázs and A. Seitz, Chem. Rev., 2010, 110, 4236-4256.

9 B. P. Johnson, G. Balázs and M. Scheer, Coord. Chem. Rev., 2006, 250, 1178-1195.

10 M. Peruzzini, L. Gonsalvi and A. Romerosa, Chem. Soc. Rev., 2005, 34, 1038-1047. 
11 M. Donath, F. Hennersdorf and J. J. Weigand, Chem. Soc. Rev., 2016, 45, 1145-1172.

12 N. A. Giffin and J. D. Masuda, Coord. Chem. Rev., 2011, 255, 1342-1359.

13 G. Balázs, A. Seitz and M. Scheer, in Comprehensive Inorganic Chemistry II, ed. J. Reedijk and K. Poeppelmeier, Elsevier, Amsterdam, 2nd edn, 2013, pp. 1105-1132, DOI: 10.1016/B978-0-08-097774-4.00143-1.

14 R. S. P. Turbervill and J. M. Goicoechea, Chem. Rev., 2014, 114, 10807-10828.

15 S. Scharfe, F. Kraus, S. Stegmaier, A. Schier and T. F. Fässler, Angew. Chem., Int. Ed., 2011, 50, 3630-3670.

16 T. F. Fässler and G. S. Armatas, Zintl Ions: Principles and Recent Developments, Springer, 2011.

17 R. J. Wilson, B. Weinert and S. Dehnen, Dalton Trans., 2018, 47, 14861-14869.

18 R. J. Wilson, N. Lichtenberger, B. Weinert and S. Dehnen, Chem. Rev., 2019, 119, 8506-8554.

19 S. C. Sevov and J. M. Goicoechea, Organometallics, 2006, 25, 5678-5692.

20 J. D. Corbett, Chem. Rev., 1985, 85, 383-397.

21 C. Liu, I. A. Popov, Z. Chen, A. I. Boldyrev and Z.-M. Sun, Chem. - Eur. J., 2018, 24, 14583-14597.

22 F. Gascoin and S. C. Sevov, Inorg. Chem., 2001, 40, 51775181.

23 A. Cisar and J. D. Corbett, Inorg. Chem., 1977, 16, 24822487.

24 F. Gascoin and S. C. Sevov, J. Am. Chem. Soc., 2000, 122, 10251-10252.

25 L. Xu, S. Bobev, J. El-Bahraoui and S. C. Sevov, J. Am. Chem. Soc., 2000, 122, 1838-1839.

26 L. Xu, A. Ugrinov and S. C. Sevov, J. Am. Chem. Soc., 2001, 123, 4091-4092.

27 A. N. Kuznetsov and T. F. Fässler, Z. Anorg. Allg. Chem., 2002, 628, 2537-2541.

28 C. Benda and T. F. Z. Fässler, Anorg. Allg. Chem., 2014, 640, 40-45.

29 L. G. Perla, A. G. Oliver and S. C. Sevov, Inorg. Chem., 2015, 54, 872-875.

30 B. Weinert, A. R. Eulenstein, R. Ababei and S. Dehnen, Angew. Chem., Int. Ed., 2014, 53, 4704-4708.

31 N. Lichtenberger, R. J. Wilson, A. R. Eulenstein, W. Massa, R. Clérac, F. Weigend and S. Dehnen, J. Am. Chem. Soc., 2016, 138, 9033-9036.

32 N. Lichtenberger, N. Spang, A. Eichhöfer and S. Dehnen, Angew. Chem., Int. Ed., 2017, 56, 13253-13258.

33 N. Lichtenberger, W. Massa and S. Dehnen, Angew. Chem., Int. Ed., 2019, 58, 3222-3226.

34 H. Ruan, L. Wang, Z. Li and L. Xu, Dalton Trans., 2017, 46, 7219-7222.

35 F. X. Pan, L. J. Li, Y. J. Wang, J. C. Guo, H. J. Zhai, L. Xu and Z. M. Sun, J. Am. Chem. Soc., 2015, 137, 1095410957.

36 I. A. Popov, F. X. Pan, X. R. You, L. J. Li, E. Matito, C. Liu, H. J. Zhai, Z. M. Sun and A. I. Boldyrev, Angew. Chem., Int. Ed., 2016, 55, 15344-15346.
37 C. Liu, N. V. Tkachenko, I. A. Popov, N. Fedik, X. Min, C. Q. Xu, J. Li, J. E. McGrady, A. I. Boldyrev and Z. M. Sun, Angew. Chem., Int. Ed., 2019, 58, 8367-8371.

38 N. V. Tkachenko, X. W. Zhang, L. Qiao, C. C. Shu, D. Steglenko, A. Munoz-Castro, Z. M. Sun and A. I. Boldyrev, Chem. - Eur. J., 2020, 26, 2073-2079.

39 M. J. Moses, J. C. Fettinger and B. W. Eichhorn, Science, 2003, 300, 778-780.

40 Y. Wang, M. Moses-DeBusk, L. Stevens, J. Hu, P. Zavalij, K. Bowen, B. I. Dunlap, E. R. Glaser and B. Eichhorn, J. Am. Chem. Soc., 2017, 139, 619-622.

41 Z. Li, H. Ruan, L. Wang, C. Liu and L. Xu, Dalton Trans., 2017, 46, 3453-3456.

42 M. Seidl, G. Balázs and M. Scheer, Chem. Rev., 2019, 119, 8406-8434.

43 D. Rottschäfer, S. Blomeyer, B. Neumann, H.-G. Stammler and R. S. Ghadwal, Chem. Sci., 2019, 10, 11078-11085.

44 D. Patel, F. Tuna, E. J. L. McInnes, W. Lewis, A. J. Blake and S. T. Liddle, Angew. Chem., Int. Ed., 2013, 52, 13334-13337.

45 C. Ganesamoorthy, C. Wölper, A. S. Nizovtsev and S. Schulz, Angew. Chem., Int. Ed., 2016, 55, 4204-4209.

46 L. Tuscher, C. Helling, C. Ganesamoorthy, J. Krüger, C. Wölper, W. Frank, A. S. Nizovtsev and S. Schulz, Chem. Eur. J., 2017, 23, 12297-12304.

47 L. Tuscher, C. Helling, C. Wölper, W. Frank, A. S. Nizovtsev and S. Schulz, Chem. - Eur. J., 2018, 24, 3241-3250.

48 C. Ganesamoorthy, J. Krüger, C. Wölper, A. S. Nizovtsev and S. Schulz, Chem. - Eur. J., 2017, 23, 2461-2468.

49 J. Krüger, C. Wölper and S. Schulz, Inorg. Chem., 2020, 59, 11142-11151.

50 C. Schoo, S. Bestgen, A. Egeberg, S. Klementyeva, C. Feldmann, S. N. Konchenko and P. W. Roesky, Angew. Chem., Int. Ed., 2018, 57, 5912-5916.

51 H. J. Breunig and R. Rösler, Chem. Soc. Rev., 2000, 29, 403410.

52 H. J. Breunig, R. Rösler and E. Lork, Angew. Chem., Int. Ed. Engl., 1997, 36, 2237-2238.

53 C. Schöttle, P. Bockstaller, R. Popescu, D. Gerthsen and C. Feldmann, Angew. Chem., Int. Ed., 2015, 54, 9866-9870.

54 C. Schoo, S. Bestgen, A. Egeberg, J. Seibert, S. N. Konchenko, C. Feldmann and P. W. Roesky, Angew. Chem., Int. Ed., 2019, 58, 4386-4389.

55 S. N. Konchenko, N. A. Pushkarevsky, M. T. Gamer, R. Köppe, H. Schnöckel and P. W. Roesky, J. Am. Chem. Soc., 2009, 131, 5740-5741.

56 N. Arleth, M. T. Gamer, R. Köppe, S. N. Konchenko, M. Fleischmann, M. Scheer and R. W. Roskey, Angew. Chem., Int. Ed., 2016, 55, 1557-1560.

57 K. M. Marczenko and S. S. Chitnis, Chem. Commun., 2020, 56, 8015-8018.

58 M. Cicač-Hudi, J. Bender, S. H. Schlindwein, M. Bispinghoff, M. Nieger, H. Grützmacher and D. Gudat, Eur. J. Inorg. Chem., 2016, 2016, 649-658.

59 A. Dragulescu-Andrasi, L. Z. Miller, B. Chen, D. T. McQuade and M. Shatruk, Angew. Chem., Int. Ed., 2016, 55, 3904-3908. 
60 M. Jo, A. Dragulescu-Andrasi, L. Z. Miller, C. Pak and M. Shatruk, Inorg. Chem., 2020, 59, 5483-5489.

61 M. Jost, L. H. Finger, J. Sundermeyer and C. von Hänisch, Chem. Commun., 2016, 52, 11646-11648.

62 R. S. P. Turbervill and J. M. Goicoechea, Organometallics, 2012, 31, 2452-2462.

63 R. S. P. Turbervill and J. M. Goicoechea, Eur. J. Inorg. Chem., 2014, 1660-1668.

64 R. S. P. Turbervill and J. M. Goicoechea, Chem. Commun., 2012, 48, 1470-1472.

65 R. S. P. Turbervill and J. M. Goicoechea, Inorg. Chem., 2013, 52, 5527-5534.

66 R. S. P. Turbervill, A. R. Jupp, P. S. B. McCullough, D. Ergöçmen and J. M. Goicoechea, Organometallics, 2013, 32, 2234-2244.

67 T. Grassl, U. Friedrich, M. Kaas and N. Korber, Z. Anorg. Allg. Chem., 2015, 641, 1203-1206.

68 H. C. Kolb, M. G. Finn and K. B. Sharpless, Angew. Chem., Int. Ed., 2001, 40, 2004-2021.

69 A. R. Jupp and J. M. Goicoechea, Angew. Chem., Int. Ed., 2013, 52, 10064-10067.

70 G. Becker, W. Schwarz, N. Seidler and M. Westerhausen, Z. Anorg. Allg. Chem., 1992, 612, 72-82.
71 F. F. Puschmann, D. Stein, D. Heift, C. Hendriksen, Z. A. Gal, H.-F. Grützmacher and H. Grützmacher, Angew. Chem., Int. Ed., 2011, 50, 8420-8423.

72 D. Heift, Z. Benkő and H. Grützmacher, Dalton Trans., 2014, 43, 831-840.

73 J. M. Goicoechea and H. Grützmacher, Angew. Chem., Int. Ed., 2018, 57, 16968-16994.

74 L. Weber, Eur. J. Inorg. Chem., 2018, 2018, 2175-2227.

75 H. Li, C. Jia, X. Meng and H. Li, Nanocrystals Front. Chem., 2019, 6, 652-667.

76 Y. Wang, B. Kong, D. Zhao, H. Wang and C. Selomulya, Nano Today, 2017, 15, 26-55.

77 K. U. D. Calvinho, A. B. Laursen, K. M. K. Yap, T. A. Goetjen, S. Hwang, N. Murali, B. Mejia-Sosa, A. Lubarski, K. M. Teeluck, E. S. Hall, E. Garfunkel, M. Greenblatt and G. C. Dismukes, Energy Environ. Sci., 2018, 11, 2550-2559.

78 M. Beekman, S. M. Kauzlarich, L. Doherty and G. S. Nolas, Materials, 2019, 12, 1139-1161.

79 M. M. Bentlohner, M. Waibel, P. Zeller, K. Sarkar, P. Müller-Buschbaum, D. Fattakhova-Rohlfing and T. F. Fässler, Angew. Chem., Int. Ed., 2016, 55, 24412445. 